\title{
Delayed recovery of left ventricular function after antithyroid treatment \\ Further evidence for reversible abnormalities of contractility in hyperthyroidism
}

\author{
J COLIN FORFAR, DAVID M MATTHEWS, ANTHONY D TOFT \\ From the Department of Cardiology, the Endocrine Unit, and the University Department of Medicine, Royal \\ Infirmary, Edinburgh
}

SUMMARY Sequential measurements of systolic time intervals, left ventricular dimensions, and the derived indices of contractility were undertaken at rest and during isometric exercise in 15 hyperthyroid patients before, during, and after antithyroid treatment. At rest hyperthyroidism was characterised by a shortened pre-ejection period and increased velocity of circumferential shortening of the left ventricle. During isometric exercise, however, the pre-ejection period increased significantly beyond that predicted for normal subjects, and the velocity of circumferential fibre shortening fell by $30 \%$. In contrast, both the pre-ejection period and the velocity of circumferential fibre shortening were unchanged during exercise after a stable euthyroid state had been achieved for at least three months. Comparison between exercise responses and thyroid status during antithyroid treatment showed that a biochemical euthyroid state may be achieved many weeks before normalisation of contractile response to exercise.

These findings support the hypothesis of reversible depression of left ventricular function in hyperthyroidism. Responses at rest principally reflect the peripheral actions of thyroid hormone excess.

Assessment of intrinsic contractile function of the heart in hyperthyroidism in man is complicated by an increase in preload from increased circulating blood volume $^{1}$ and a substantial fall in afterload from reduced peripheral vascular resistance. ${ }^{2} \mathrm{~A}$ recent study noted a $34 \%$ increase in left ventricular end diastolic volume and a $46 \%$ fall in peripheral vascular resistance in hyperthyroid subjects compared with euthyroid subjects atrially paced to the same heart rate. ${ }^{3}$ The interpretation of indices of ventricular function at rest in hyperthyroidism is, therefore, unreliable. Most experimental studies in vitro have reported enhanced myocardial contractility in hyperthyroid states, ${ }^{4-6}$ although the muscle may more readily fatigue, ${ }^{78}$ but in these and in other experimental studies with an intact circulation changes in thyroid status have been induced over a short period of time (weeks) and, therefore, may not be compar-

Requests for reprints to Dr J C Forfar, Cardiac Department, John Radcliffe Hospital, Oxford OX3 9DU.

Accepted for publication 5 April 1984 able with spontaneous hyperthyroidism in man.

Isometric exercise is a convenient means of stressing the myocardium and increases oxygen consumption through a combination of increased afterload, inotropic activity, and heart rate. During such exercise repeated non-invasive measurements of myocardial dimensions and contractile function may be made by echophonocardiography. Since we have recently found abnormal left ventricular function during dynamic exercise in hyperthyroidism, ${ }^{9}$ the purpose of this study was to examine simultaneously isovolumetric and ejection phase indices of myocardial contractility during isometric exercise in hyperthyroid patients before and at intervals during or after antithyroid treatment. In addition, the effect of autonomic blockade was examined to determine the influence of vagal and sympathetic activity on the responses observed. The study was designed both to confirm or refute the abnormalities on dynamic exercise and to determine prospectively whether a direct temporal relation existed between concentrations of thyroid hormones and myocardial contractile function as claimed by other investigators. ${ }^{1011}$ 


\section{Patients and methods}

Fifteen hyperthyroid patients (all women, mean age 45 (range 23-65 years) years) were studied in the untreated hyperthyroid state and at intervals during or after antithyroid treatment. Eleven patients had Graves's disease, and four had a multinodular goitre. Hyperthyroidism was diagnosed clinically and by raised concentrations of plasma total thyroxine $\left(T_{4}\right)$ and triiodothyronine $\left(\mathrm{T}_{3}\right)$ associated with an absent response of plasma thyrotropin 20 minutes after the intravenous injection of $200 \mu \mathrm{g}$ of thyrotropin releasing hormone. No patient had evidence of concurrent cardiovascular disease based on clinical examination, electrocardiography, and chest radiography. All patients were restudied when they had been biochemically euthyroid for at least three months. Eleven patients received iodine 131, two patients received carbimazole, and one underwent subtotal thyroidectomy. In one patient hyperthyroidism resolved spontaneously. Nine of these patients were studied at 3-6 week intervals until euthyroid.

At each attendance blood was taken for estimation of plasma total $T_{4}, T_{3}$, and plasma thyrotropin immediately before the echophonocardiographic study. Plasma thyroid hormones and thyrotropin were measured by specific radioimmunoassay. 1213 All patients gave informed consent and were familiarised with the recording equipment before the first study. After a 10 minute rest period and insertion of a venous cannula, systolic time interval measurements were recorded in the supine position according to established techniques ${ }^{14}$ using a Kontron Irex Mark III phased array sector scanner with phonocardiography. All recordings were made at a paper speed of 100 $\mathrm{mm} / \mathrm{s}$ and averaged over 10 cardiac cycles. From simultaneous recording of the electrocardiogram (lead II), phonocardiogram, and carotid pulse tracings the following indices were measured: $(a)$ left ventricular ejection time-from the beginning of the initial upstroke to the trough of the incisural notch of the carotid pulse tracing; $(b)$ total electromechanical systole $\left(\mathrm{QS}_{2}\right)$-from the beginning of the $\mathrm{Q}$ wave of the electrocardiogram to the first high frequency component of the aortic second heart sound; and $(c)$ electromechanical delay $\left(\mathrm{QS}_{1}\right)$-from the beginning of the $\mathrm{Q}$ wave of the electrocardiogram to the first high frequency component of the first heart sound. From these measurements the pre-ejection period and the isovolumetric contraction time were determined as shown in Fig. 1. Heart rate corrected indices for left ventricular ejection time, $\mathrm{QS}_{2}$, and pre-ejection period at rest were derived from the standard regression equations of Weissler et al based on measurements from resting normal subjects ${ }^{15}$ and from the studies of Lindquist $e t$ al on normal subjects during isometric exercise. ${ }^{16}$

Echocardiography was performed from the third or
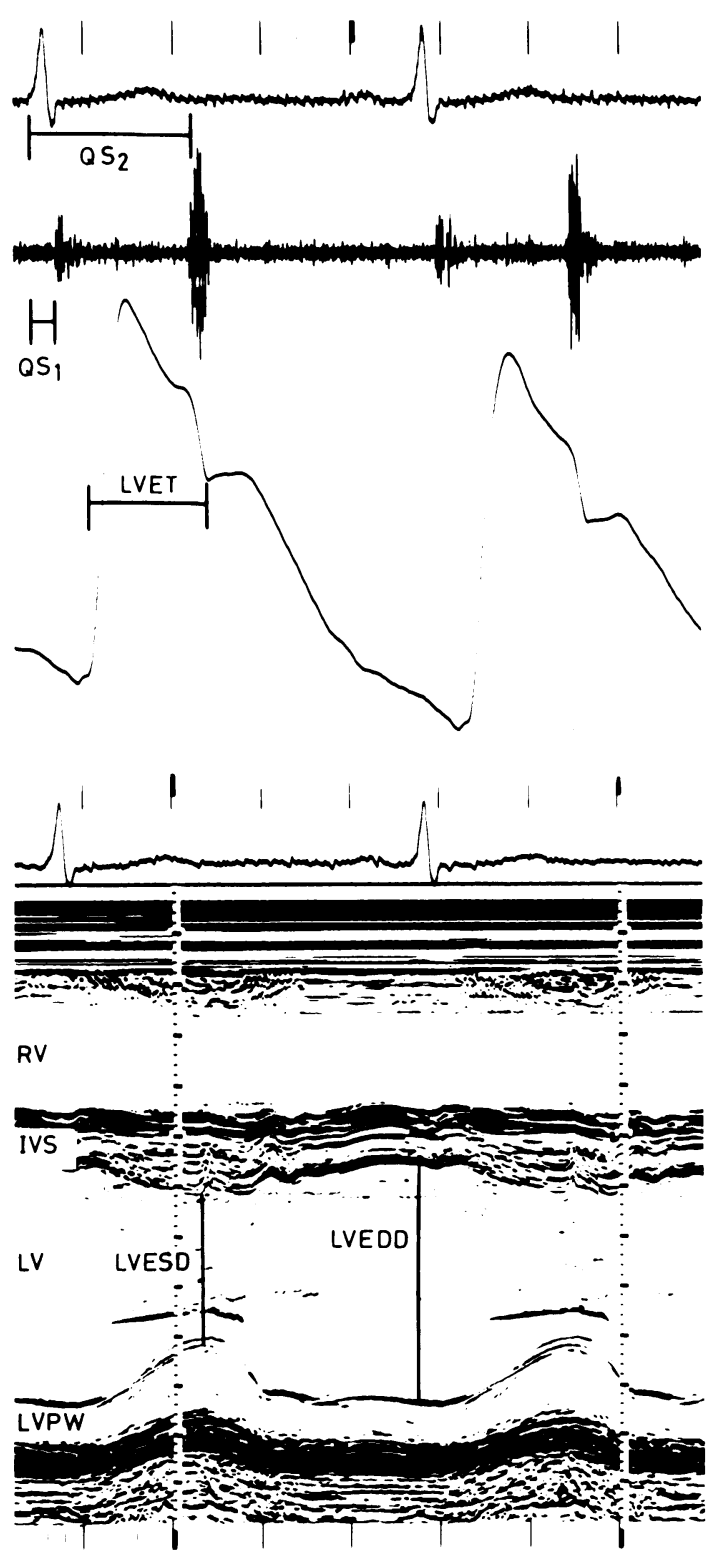

Fig. 1 Simultaneous determination of systolic time intervals and ventricular dimensions from combined echophonocardiography. LVET, left ventricular ejection time; $Q S_{1}$, electromechanical delay; PEP, pre-ejection period; ICT, isovolumetric contraction time; LVEDD/LVESD, left ventricular end diastolic/end systolic dimensions; $R V$, right ventricle; IVS, interventricular septum; $L V$, left ventricle; $L V P W$, left ventricular posterior wall. $P E P=Q S_{2}-L V E T$; $I C T=P E P-Q S_{1}$. 
fourth intercostal space with the patient either supine or in the $30^{\circ}$ left lateral position immediately after the systolic time interval measurements. An initial cross sectional image orientated the $M$ mode examination of the left ventricle with the ultrasound beam directed at the chamber between the mitral valve and papillary muscle echoes (Fig. 1). ${ }^{17}$ The left ventricular end diastolic dimension (LVEDD) was taken from the trailing edge of the left side of the interventricular septum to the leading edge of the posterior endocardial echo at the $\mathbf{R}$ wave of the electrocardiogram and the left ventricular end systolic dimension (LVESD) from the same sites at the time of peak upward motion of the posterior left ventricular endocardium. ${ }^{18}$ From these measurements the mean velocity of circumferential shortening of the left ventricle $(\mathrm{Vcf})$ was derived as follows: $\mathrm{Vcf}=$ (LVEDD-LVESD)/ $($ LVEDD $\times$ LVET) (circumferences per $s$ ). The patient and transducer position for optimal recording were noted initially and duplicated for subsequent echocardiograms. All values were averaged over five consecutive cardiac cycles. Systolic blood pressure was determined at rest with a mercury sphygmomanometer using the arm not in use for the isometric test.

After the basal measurements had been made, isometric exercise was performed with a handgrip dynamometer. After determination of the maximal voluntary contraction each patient squeezed the dynamometer at $30 \%$ of maximum contraction for three minutes. Systolic blood pressure measurements were repeated after two minutes and the echophonocardiographic analyses repeated between the second and third minutes of handgrip.

After a further 15 minute rest period 14 patients were given propranolol $(0.15 \mathrm{mg} / \mathrm{kg})$ intravenously over five minutes followed by intravenous atropine $(0.02 \mathrm{mg} / \mathrm{kg})$ over a similar period. Fifteen minutes later the above protocol was repeated both at rest and during isometric exercise.

Identical studies were undertaken at intervals during antithyroid treatment and when a euthyroid state had been achieved for at least three months. Acute autonomic blockade was omitted in one patient because of mild asthma and in a second after dizziness during the initial study. In addition, two patients receiving oral beta adrenoceptor blocking drugs as part of the routine early management of hyperthyroidism were not subject to additional beta adrenoceptor blockade during antithyroid treatment, the data being included with the other studies during autonomic blockade. Echophonocardiographic measurements were, therefore, repeated at intervals over several months. Although reproducibility studies were not performed, others 111419 have shown a small standard deviation for systolic time intervals (for example $5 \mathrm{~ms}$ for left ventricular ejection time; $4 \mathrm{~ms}$ for pre-ejection period) and for velocity of circumferential fibre shortening $(0.05$ circumferences per $s)$ when repeated at intervals over weeks in the same subjects. A preliminary study of four normal subjects on four separate occasions using the above protocol showed similar day to day variability in these indices. All measurements of ventricular function during or after antithyroid treatment were made without knowledge of thyroid hormone concentrations.

For statistical analysis Student's $t$ test was used for pair differences. For correlations between thyroid hormone concentrations and indices of ventricular function a linear regression coefficient with least squares analysis and computed $t$ statistic after semilog transformation was used. Data are expressed as mean (SEM).

\section{Results}

The Table gives details of systolic blood pressure, heart rate, systolic time interval indices, ventricular dimensions, and the derived indices of ventricular function at rest and during isometric exercise in the hyperthyroid and euthyroid state before and after autonomic blockade at rest and during exercise.

\section{HYPERTHYROID STATE}

At rest left ventricular ejection time index was not significantly different from that predicted (418 (11) $\mathrm{ms}$ ) either before or during autonomic blockade (Table). During isometric exercise this value did not differ significantly from the predicted value (379 (14) $\mathrm{ms}$ ) before or during autonomic blockade. At rest mean electromechanical systole index $\left(\mathrm{QS}_{2} \mathrm{I}\right)$ was significantly less than predicted $(549(3) \mathrm{ms} ; \mathrm{p}<0.01)$. In contrast, however, during isometric exercise this value was significantly greater than predicted (514 (6) ms; $p<0.05$ ). During autonomic blockade this value at rest was unchanged, but it was also significantly prolonged during isometric exercise.

As a consequence of the changes in electromechanical systole, pre-ejection period index was less than predicted (133 (10) $\mathrm{ms}$ ) in the resting hyperthyroid state before and during autonomic blockade $(p<0.005)$. During exercise, this value increased substantially $(p<0.005)$. The exercise value was $9 \mathrm{~ms}$ longer than predicted (135 (13) ms) from the regression equation for normal subjects. This increase resulted mainly from an increase in isovolumetric contraction time (Table). The pattern of prolongation in pre-ejection period index with exercise was similar during autonomic blockade. The ratio of pre-ejection period to left ventricular ejection time increased during exercise before and after autonomic blockade (Table). 
Table 1 Systolic blood pressure, heart rate, systolic time interval responses, left ventricular dimensions, and derived indices of left ventricular (LV) function in response to isometric exercise $(E x)$ and autonomic blockade in patients in the untreated hyperthyroid and euthyroid state. Values are means (SEM)

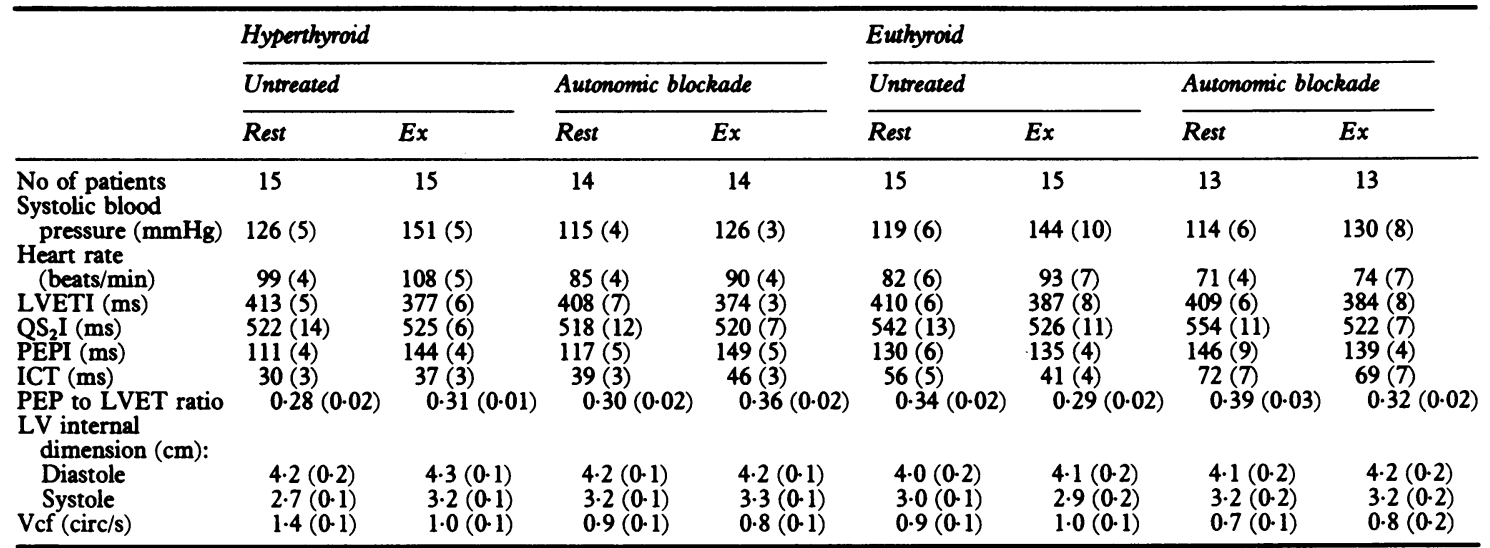

LVETI, left ventricular ejection time index; $\mathrm{QS}, \mathrm{I}$, electromechanical systole index; PEPI, pre-ejection period index; ICT, isovolumetric contraction time; Vcf, velocity of circumferential fibre shortening.

Left ventricular end diastolic dimensions were uninfluenced by exercise or autonomic blockade (Table). Exercise and autonomic blockade alone increased left ventricular end systolic dimensions $(p<0.01)$ with a further minor increase in combination $(3 \cdot 3(0 \cdot 1) \mathrm{cm})$. As a result, mean velocity of circumferential fibre shortening decreased during exercise by $30 \%$ before and by $13 \%$ after autonomic blockade. As might be expected the resting value also decreased (by 33\%) after autonomic blockade.

The changes in these indices at rest and during exercise are summarised in Fig. 2. In the hyperthyroid state isometric exercise was associated with an increase in pre-ejection period index from $21 \mathrm{~ms}$ less than predicted to $9 \mathrm{~ms}$ greater than predicted $(p<0.005)$, the exercise induced prolongation in preejection period index being similar after autonomic blockade.

\section{ESTABLISHED EUTHYROID STATE}

The same indices of ventricular function in the same patients after a euthyroid state had been achieved for at least three months are given in the Table and summarised at rest and during exercise in Fig. 2. Compared with the hyperthyroid state resting left ventricular ejection time index was unchanged, but $\mathrm{QS}_{2} \mathrm{I}$ was significantly prolonged both before $(+20(11) \mathrm{ms}$, $\mathrm{p}<0.05)$ and after $(+36(12) \mathrm{ms}, \mathrm{p}<0.02)$ autonomic blockade. An appreciable prolongation of the preejection period index was also observed in the euthyroid patients at rest $(+19(6) \mathrm{ms}$ before and +29 (9) ms after autonomic blockade, $\mathrm{p}<0.01$ ). During exercise left ventricular ejection time index in the euthyroid state was slightly longer than when hyper- thyroid, but results did not achieve statistical significance at the $5 \%$ level. In direct contrast to the

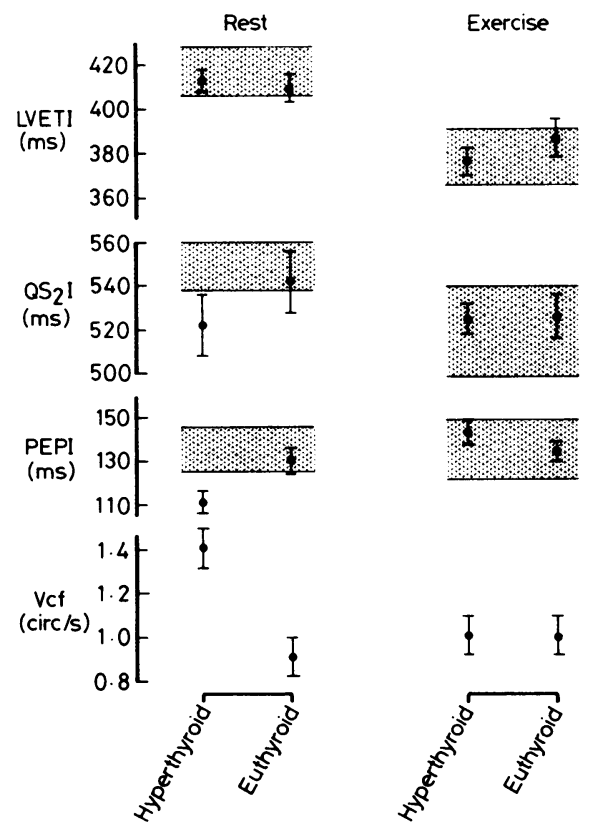

Fig. 2 Mean (SEM) values of systolic time interval and velocity of circumferential shortening of the left ventricle in 15 hyperthyroid patients and the same patients euthyroid at rest and during isometric exercise before and after autonomic blockade. Hatched areas denote predicted values (1SD) for normal subjects. LVETI, left ventricular ejection time index; $Q S_{2} I$, electromechanical systole index; PEPI, pre-ejection period index; Vcf, velocity of circumferential fibre shortening. 
hyperthyroid data, however, the exercise pre-ejection period index was shorter in the euthyroid state both before $(-9(4) \mathrm{ms}, \mathrm{p}<0.05)$ and after $(-10(5) \mathrm{ms}$; $p<0.05)$ autonomic blockade. It is likely that most of the differences are accounted for by changes in isovolumetric contraction time (Table).

Mean resting velocity of circumferential fibre shortening fell by $36 \%$ in the euthyroid state (Table), but in contrast to the exercise induced fall in the hyperthyroid state this value did not change with exercise either before or after autonomic blockade. Propranolol and atropine increased left ventricular end systolic diameter at both levels of thyroid function, but end diastolic diameter was unchanged. There was a trend for increased left ventricular end diastolic diameter in the hyperthyroid state, but this increase did not achieve statistical significance $(0.1>p>0.05)$. Left ventricular end systolic diameter was less than control values in the hyperthyroid state at rest but slightly greater than control values during exercise. Thus the mean value on exercise was similar in both the hyperthyroid and euthyroid states (Table and Fig. 2).

All the systolic time interval indices in the euthyroid state at rest and during exercise before autonomic blockade were within one standard deviation of the expected mean based on an analysis of normal subjects.

\section{VENTRICULAR FUNCTION-THYROID HORMONE RELATION}

A close inverse correlation was observed between resting pre-ejection period index and concentrations of total thyroid hormones in the hyperthyroid and euthyroid states both before $(r=0.71 ; p<0.001)$ and during $(r=0.80 ; p<0.001)$ autonomic blockade. A similar but direct relation was observed for the velocity of circumferential fibre shortening both before $(\mathrm{r}=0.51 ; \mathrm{p}<0.01)$ and during $(\mathrm{r}=0.53 ; \mathrm{p}<0.01)$ autonomic blockade.

In contrast to the resting data, during exercise neither isovolumetric nor ejection phase indices of ventricular function correlated significantly with plasma concentrations of thyroid hormones before or after autonomic blockade. The change in pre-ejection period index and velocity of circumferential fibre shortening with exercise, however, correlated with thyroid hormone concentration at all levels of thyroid function, the relation being closer after autonomic blockade (Fig. 3).

\section{VENTRICULAR FUNCTION DURING ANTITHYROID TREATMENT}

In four of the nine patients studied on between four and six occasions during antithyroid treatment, a temporal dissociation was evident between the fall in

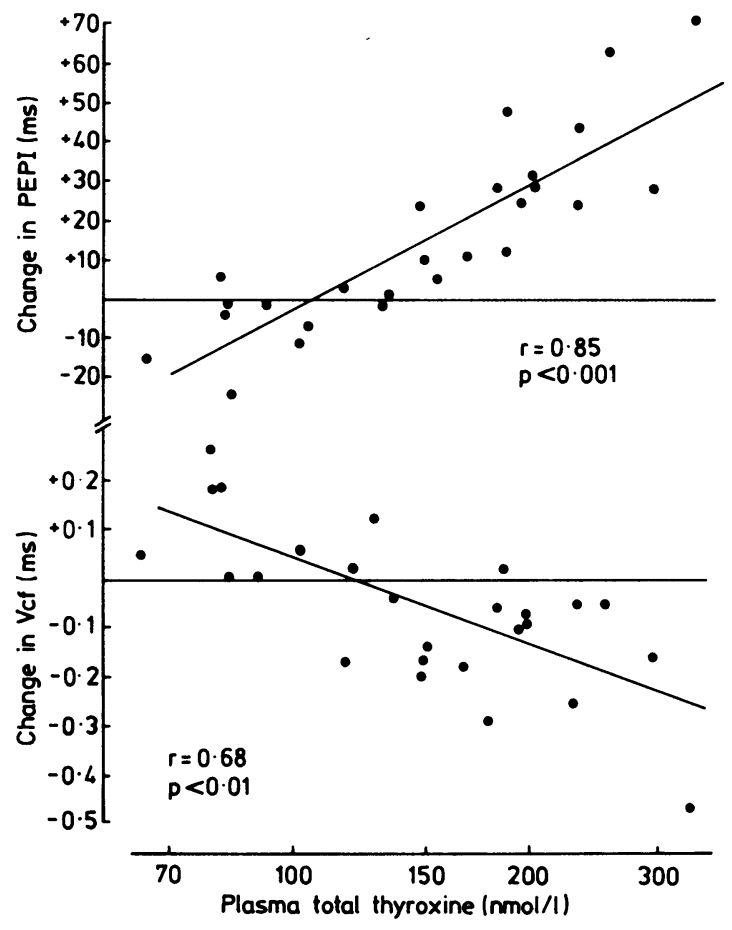

Fig. 3 Relation between plasma thyroxine concentrations and exercise induced changes in isovolumetric (PEPI) and ejection ( $V c f)$ phase indices of ventricular function during autonomic blockade in patients.

thyroid hormone concentrations towards normal and improvement in myocardial contractile function during exercise. Fig. 4 shows two examples of this dissociation. In the first patient (Fig. 4a) thyroid hormone concentrations returned to normal 60 days after antithyroid treatment (iodine 131), but indices of ventricular function during exercise remained abnormal for several weeks thereafter and did not come within the expected normal range until $\mathbf{1 4 0}$ days after initial radioiodine treatment. A similar dissociation was evident in a second patient who developed hypothyroidism after radioiodine (Fig. 4b). Exercise responses during the third study when the patient was biochemically hypothyroid were similar to responses during hyperthyroidism but had normalised by the fourth study despite a similar depression of thyroid hormone activity.

\section{Discussion}

Several previous studies have reported similar changes in resting systolic time interval and echocardiographic measurements of ventricular function to those reported here. Most investigators have shown reductions in pre-ejection period and duration of elec- 


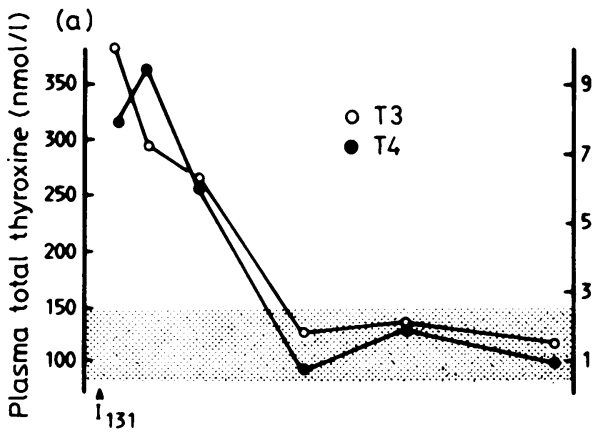

(b)
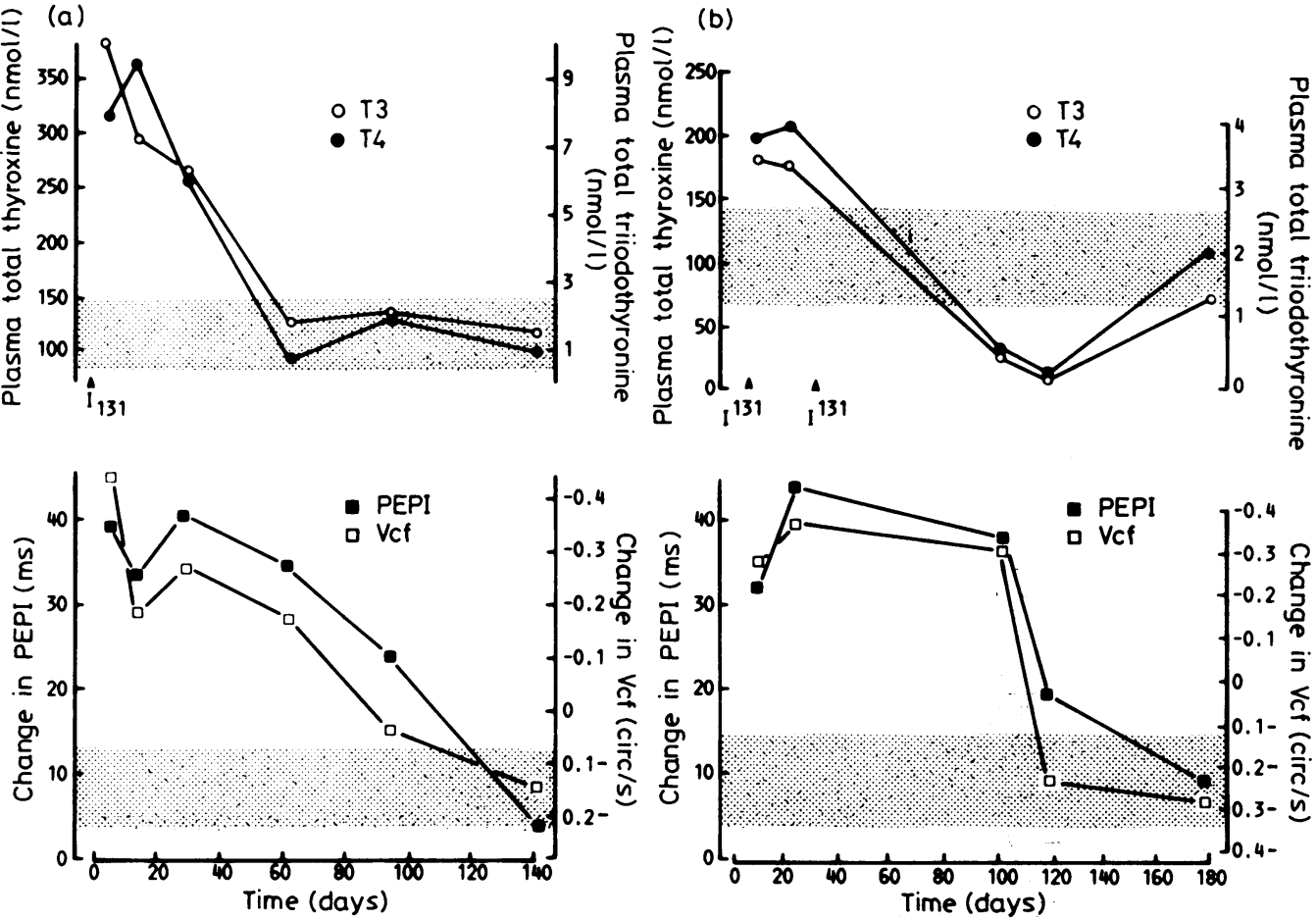

Fig. 4 Comparison between thyroid hormone concentrations and responses of isovolumetric and ejection phase indices of ventricular contractility to exercise in two hyperthyroid patients during antithyroid treatment. A positive change in pre-ejection period index (PEPI) with exercise and a negative change in mean velocity of circumferential of shortening (Vcf) with exercise both represent reductions in myocardial contractile function.

tromechanical systole in hyperthyroidism $101120-22$ with usually little change in left ventricular ejection time. In all studies the pre-ejection period has been $20-40 \mathrm{~ms}$ less than that predicted for heart rate, a reduction that has generally been interpreted as a consequence of an increase in intrinsic myocardial contractile activity. Similarly, echocardiographic indices of myocardial contractile function at rest have shown augmented velocity of shortening of the left ventricle returning to normal in the euthyroid state. ${ }^{1123}$

The interpretation of these data in terms of increased intrinsic contractile activity of the heart is simplistic and cannot be supported in the light of the peripheral haemodynamic effects of thyroid hormones. Thus a substantial reduction in peripheral vascular resistance at rest ${ }^{23}$ and increase in circulating volume $^{1}$ would tend to shorten isovolumetric phase indices and increase ejection phase indices of contractility independent of any true change in the contractile state of the heart. In this regard, it is of interest that the extent of shortening in pre-ejection period in hyperthyroidism is considerably greater than that shown with specific positive inotropic agents. ${ }^{24} \mathrm{Car}$ diac output may be normal in hyperthyroid patients with congestive heart failure, ${ }^{25}$ contrasting with an increased output in patients without evidence of heart failure. Although the maximum rate of rise of left ventricular pressure and left ventricular ejection fraction were increased in hyperthyroidism at rest in the study of Merillon et al, ${ }^{3}$ a comparison with euthyroid control subjects atrially paced to the same heart rate showed that the ejection fraction, rate of rise of left ventricular pressure as a proportion of the total pressure, velocity of circumferential fibre shortening, and the ratio of left ventricular end systolic pressure to volume were similar in both groups; the last measurement in particular is a sensitive index of performance of the left ventricular pump. ${ }^{26}$ Dilatation of the left ventricle with an increased end diastolic volume and a normal or reduced left ventricular ejection fraction has been reported in hyperthyroidism. ${ }^{27}$ Interpretation of resting indices of ventricular function is thus difficult in this condition.

In contrast, during isometric exercise, this study has shown substantial prolongation of the pre-ejection period index and a fall in the velocity of circumferential fibre shortening in hyperthyroid patients. The isovolumetric phase index (pre-ejection period index) 
increased with exercise to a level greater than that predicted for heart rate in normal subjects using standard regression equations. ${ }^{16}$ The reduction in ejection phase index of contractility (velocity of circumferential fibre shortening) during exercise in the hyperthyroid state contrasted with no change in the velocity of ventricular muscle shortening in the euthyroid state. Both of these independent observations suggest impairment of intrinsic myocardial contractile performance during exercise in hyperthyroidism and support our earlier findings. ${ }^{9}$ Prolongation in preejection period index during exercise in the hyperthyroid state contrasts with either no change or a reduction in this measurement in the same patients when euthyroid and in other studies in normal subjects and those with coronary artery disease. ${ }^{28}$ Invasive assessment of responses to isometric hand grip exercise has shown no changes in stroke volume or stroke index in normal subjects, contrasting with a fall in these indices in patients with heart disease. ${ }^{29}$

Several studies have shown a correlation between concentrations of peripheral thyroid hormones and indices of ventricular function at rest, 101120 a relation confirmed here. It is likely, however, in view of responses to exercise that this reflects dose dependent effects of thyroid hormone on peripheral vascular haemodynamics rather than on the heart itself. Many of the clinical features of hyperthyroidism probably reflect this action of thyroid hormone excess. ${ }^{3}$ No such relation for pre-ejection period index and velocity of circumferential fibre shortening is evident during exercise, although the change in these indices during exercise is related to concentrations of thyroid hormones (Fig. 3) such that the greater the concentrations of hormones the greater the impairment of the exercise response. These results suggest that at least a component of this abnormal response to exercise is dependent on the degree of hyperthyroidism, as reflected by peripheral hormone concentrations.

Acute autonomic blockade and antithyroid treatment with the establishment of a euthyroid state have fundamentally different actions on the heart in hyperthyroidism. Although both interventions were associated with an increase in pre-ejection period index the magnitude of change in this value was over three times greater after antithyroid treatment than after autonomic blockade. Changes in resting velocity of circumferential fibre shortening were, however, similar after autonomic blockade and antithyroid treatment, highlighting the importance of peripheral factors in determining isovolumetric indices of ventricular function. The increase in resting left ventricular end systolic diameter was the major factor contributing to the fall in velocity of circumferential fibre shortening after autonomic blockade, whereas the fall after antithryoid treatment depended on a combina- tion of a decrease in left ventricular end diastolic diameter and an increase in end systolic diameter (Table). These changes agree with the results of the invasive studies of Merillon et al. ${ }^{3}$ During exercise the contrast between the values after autonomic blockade and those after antithyroid treatment is more pronounced. Directional changes in indices of ventricular function were not influenced by autonomic blockade in hyperthyroidism, with the increase in pre-ejection period index and reduction in velocity of circumferential fibre shortening during exercise being similar to those before autonomic blockade. Antithyroid treatment, however, led to normalisation of responses to exercise, provided that a euthyroid state had been achieved for several months.

Although the magnitude of reduction in myocardial contractile activity during exercise was related to peripheral hormone concentrations in the untreated hyperthyroid state (Fig. 3), the relation broke down during antithyroid treatment (Fig. 4), suggesting that factors other than hormone concentration determined contractile activity during this time. This delayed normalisation of left ventricular function supports the concept of structural changes in the hyperthyroid heart (determined perhaps as much by the duration of hyperthyroidism as by the concentrations of thyroid hormones) that resolve at a rate appreciably slower than the hyperthyroidism itself. Delays of up to two months in the normalisation of the arterial sound times in hyperthyroid subjects studied repeatedly during antithyroid treatment, ${ }^{30}$ and normalisation of plasma thyroxine concentrations some weeks before that of the pre-ejection period index in hypothyroid patients during thyroxine replacement treatment ${ }^{22}$ are in keeping with this concept. The mechanism of abnormal contractile function in the hyperthyroid heart is unknown but may be related to the recently described extensive but reversible replacement of the normal myosin isoenzyme. ${ }^{31}$

The present study and our earlier findings permit the development of a new hypothesis of myocardial function in hyperthyroidism - namely, that left ventricular function is reversibly depressed, as evidenced by abnormalities in isovolumetric and ejection phase indices of contractile activity during static and dynamic exercise. Ventricular function returns to normal only after a stable euthyroid state has been achieved for at least three months. The apparent changes in indices of contractile activity at rest are primarily related to the profound peripheral effects of thyroid hormones. Autonomic blockade causes similar reductions in myocardial contractile function in the hyperthyroid and euthyroid state without influencing directional responses to exercise. No evidence of a specific thyroid-autonomic interaction is observed. 
This hypothesis has the advantage of explaining the well established clinical observation of heart failure in uncomplicated hyperthyroidism 252732 : it may be considered one end of a range of depression of myocardial contractility rather than an idiosyncratic reaction to thyroid hormone excess. These studies are, however, at variance with results in experimental hyperthyroidism suggesting that experimental models may have limited application to man either because of the uniformly short duration of thyroid hormone feeding or because of cardiodepressant factors operative clinically but not when the disease is mimicked by thyroxine or triiodothyronine administration. Ideally, further resting studies in the hyperthyroid and euthyroid states during similar loading conditions of the heart would be necessary to confirm abnormal ventricular function at rest, but this would require combined volume loading and substantial afterload reduction in the latter state, both of which would be difficult to achieve. These findings underline the importance of early diagnosis and treatment of hyperthyroidism as left untreated the abnormalities in myocardial function described may progress to overt cardiac decompensation.

\section{References}

1 Gibson JG, Harris AW. Clinical studies on the blood volume: V Hyperthyroidism and myxedema. 7 Clin Invest 1939; 18: 59-65.

2 DeGroot WJ, Leonard JJ. Hyperthyroidism as a high cardiac output state. Am Heart f 1970; 79: 265-75.

3 Merillon JP, Passa P, Chastre J, Wolf A, Gourgon R. Left ventricular function in hyperthyroidism. Br Heart $\mathcal{F} 1981$; 46: 13743.

4 Buccino RA, Spann JF Jr, Pool PE, Sonnenblick EH, Braunwald E. Influence of the thyroid state on the intrinsic contractile properties and energy stores of the myocardium. $\mathcal{F}$ Clin Invest 1967; 46: $1669-82$.

5 Murayama M, Goodkind MJ. Effect of thyroid hormone on the frequency-force relationship of atrial myocardium from the guinea pig. Circ Res 1968; 23: 743-51.

6 Pannier JL. The influence of thyroid hormone on myocardial contractility. Arch Int Physiol 1968; 76: 477-90.

7 Korecky B, Beznak M. Effect of thyroxine on growth and function of cardiac muscle. In: Alpert NR, ed. Cardiac hypertrophy. New York: Academic Press, 1971: 55.

8 Taylor RR. Contractile properties of cardiac muscle in hyperthyroidism: analysis of behaviour of hyperthyroid cat papillary muscle in vitro relevant to thyrotoxic heart disease. Circ Res 1970; 27: 539-49.

9 Forfar JC, Muir AL, Sawers JSA, Toft AD. Abnormal left ventricular function in hyperthyroidism: evidence for a possible reversible cardiomyopathy. $N$ Engl $₹$ Med 1982; 307: 1165-70.

10 Paulus WJ, Ranquin R, Parizel G. Systolic time intervals: a valuable parameter of thyroid function. Angiology 1980; 31: 100-8.

11 Cohen MV, Schulman IC, Spenillo A, Surks MI. Effects of thyroid hormone on left ventricular function in patients treated for thyrotoxicosis. Am f Cardiol 1981; 48: 33-8.

12 Seth J, Toft AD, Irvine WJ. Simple solid-phase radioimmunoassays for total tri-iodothyronine and thyroxine in serum, and their clinical evaluation. Clin Chim Acta 1976; 68: 291-301.
13 Irvine WJ, Toft AD, Hunter WM, Kirkham KE. An assessment of plasma TSH radioimmunoassay and of the TSH stimulation test in the diagnosis of 100 consecutive patients with suspected hypothyroidism. Clin Endocrinol (Oxf) 1973; 2: 135-9.

14 Lewis RP, Leighton RF, Forester WF, Weissler AM. Systolic time intervals. In: Weissler AM, ed. Nonirvasive cardiology. New York: Grune and Stratton, 1974: 311.

15 Weissler AM, Harris WS, Schoenfeld CD. Systolic time intervals in heart failure in man. Circulation 1968; 37: 149-59.

16 Lindquist VAY, Spangler RD, Blount SG Jr. A comparison between the effects of dynamic and isometric exercise as evaluated by the systolic time intervals in normal man. Am Heart $f$ 1973; 85: 227-36.

17 Sahn DJ, DeMaria A, Kisslo J, Weyman A. Recommendations regarding quantification in M-mode echocardiography: results of a survey of echocardiographic measurements. Circulation 1978; 58: 1072-83.

18 Feigenbaum H. Echocardiography 3rd ed. Philadelphia: Lea and Febiger, 1981: 119.

19 Clark RD, Korcuska K, Cohn K. Serial echocardiographic evaluation of left ventricular function in valvular disease, including reproducibility guidelines for serial studies. Circulation 1980; 62: 564-75.

20 Parisi AF, Hamilton BP, Thomas CN, Mazzaferri EL. The short cardiac pre-ejection period: an index to thyrotoxicosis. Circulation 1974; 49: 900-4.

21 Burckhardt D, Staub JJ, Kraenzlin M, Raeder E, Engel U, Cloppenburg $P$. The systolic time intervals in thryroid dysfunction. Am Heart f 1978; 95: 187-96.

22 Chakravarty J, Guansing AR, Chakravarty S, Hughes CV. Systolic time intervals (STI) as indicators of myocardial thyroid hormone effect: a correlative study in hypothyroid and hyperthyroid patients. Acta Endocrinol (Kbh) 1978; 87: 507-15.

23 Lewis BS, Ehrenfeld EN, Lewis N, Gotsman MS. Echocardiographic LV function in thyrotoxicosis. Am Heart f 1979; 97: 4608.

24 Weissler AM, Lewis RP, Leighton RF. The systolic time intervals as a measure of left ventricular performance in man. In: Yu PN, Goodwin JF, eds. Progress in cardiology . vol 1. Philadelphia: Lea and Febiger, 1972: 155-83.

25 Graettinger JS, Muenster JJ, Selverstone LA, Campbell JA. A correlation of clinical and hemodynamic studies in patients with hyperthyroidism with and without congestive heart failure. $f \mathrm{Clin}$ Invest 1959; 38: 1316-27.

26 Suga H, Sagawa K. Instantaneous pressure-volume relationships and their ratio in the excised, supported canine left ventricle. Circ Res 1974; 35: 117-26.

27 Ueda H, Sugishita Y, Nakanashi A, et al. Clinical studies on the cardiac performance by means of transeptal left heart catheterisation II: Left ventricular function in high output heart diseases, especially hyperthyroidism. fpn Heart $\mathcal{f}$ 1965; 6: 396-406.

28 Siegel W, Gilbert CA, Nutter DO, Schlant RC, Hurst JW. Use of isometric handgrip for the indirect assessment of left ventricular function in patients with coronary atherosclerotic heart disease. Am $\mathcal{F}$ Cardiol 1972; 30: 48-54.

29 Helfant RH, DeVilla MA, Meister SG. Effect of sustained isometric handgrip exercise on left ventricular performance. Circulation 1971; 44: 982-93.

30 Young RT, Van Herle AJ, Rodbard D. Improved diagnosis, and management of hyper- and hypothyroidism by timing the arterial sounds. F Clin Endocrinol Metab 1976; 42: 330-40.

31 Litten RZ, Martin BJ, Low RB, Alpert NR. Altered myosin isoenzyme patterns from pressure-overloaded and thyrotoxic hypertrophied rabbit hearts. Circ Res 1982; 50: 856-64.

$32 \mathrm{Ikram} \mathrm{H}$. Haemodynamic effects of beta-adrenergic blockade in hyperthyroid patients with and without heart failure. $\mathrm{Br} \mathrm{Med} \mathcal{F}$ 1977 ; i: $1505-7$. 